\title{
Is Endoplasmic Reticulum Stress linked to the Pathogenesis of Pemphigus Vulgaris?
}

\section{Authors:}

Chrysovalantou Mihailidou, Hippokratis Kiaris ${ }^{\mathrm{a}, \mathrm{b}, \mathrm{c}}$

Ioulia Chatzistamou $^{\mathrm{d}}$

\section{Authors Note:}

${ }^{a}$ Department of Biochemistry, University of Athens Medical School, Athens, Greece

${ }^{\mathrm{b}}$ Department of Drug Discovery and Biomedical Sciences, University of South Carolina, SC, USA

${ }^{c}$ Peromyscus Genetic Stock Center, Office of Research, University of South Carolina, SC, USA

${ }^{\mathrm{d}}$ Department of Pathology, Microbiology and Immunology, University of South Carolina School of Medicine, SC, USA

Abbreviated title:

ER stress and Pemphigus Vulgaris

\section{Correspondence:}

Dr Ioulia Chatzistamou

(chatzistamou@uscmed.sc.edu),

Dept. of Pathology, Microbiology and Immunology, University of South Carolina, School of Medicine, 6439 Garners Ferry Rd, Bldg \#1, Room B32, Columbia, SC29208, USA, (803) 216-3467 Office, (803) 216-3413 Fax

\section{Disclosure statement:}

The authors have nothing to declare

\section{Abstract}

Pemphigus vulgaris (PV) is an organspecific autoimmune blistering disease, affecting the skin and the mucous membranes. Despite the breakthroughs in therapy for advanced disease in the recent years, the management of PV remains challenging with poor prognosis and limited therapeutic options. Cloning of cDNAs encoding pemphigus antigens has provided ample evidence that $\operatorname{IgG}$ autoantibodies recognize the desmogleins (DSGs) that are found in the adhering junctions, the desmosomes. Binding of such IgGs in the DSGs results in the weakening of intercellular adhesion of keratinocytes in the upper part of the epidermis and eventually to acantholysis. Desmosomes have instrumental role as a protective barrier in maintaining the integrity and function of the epidermis and the mucous epithelia. Mechanistically, the production of IgG autoantibodies against DSG1 and DSG3 is linked to disease pathogenesis. Recently, endoplasmic reticulum (ER) stress, a highly conserved cellular stress response, has been proposed to play a role in the development and progression of PV. ER stress triggers the activation of several intracellular signaling pathways that collectively constitute the unfolded protein response (UPR) that initially aims to restore homeostatic balance while subsequently becomes proapoptotic. The discovery that ER stress occurs during PV development implies that deregulated UPR may contribute to the pathogenesis of the disease. Future studies should be directed toward understanding how modulation of the ER can provide new therapeutic possibilities for the treatment of PV patients.

Key Words: Pemphigus Vulgaris (PV), desmogleins (DSGs), Endoplasmic Reticulum (ER) stress ER-stress, Unfolded protein response (UPR), C/EBP-homologous protein (CHOP), autoimmune disease 


\section{Is Endoplasmic Reticulum Stress linked to the Pathogenesis of Pemphigus Vulgaris?}

\section{Pemphigus vulgaris: present-day portrait \\ 1.1. Pemphigus: Historical Perspective}

The term pemphigus originates from the Greek word pemphix, meaning blister or bubble. It was fully recognized and described well, almost two centuries ago in 1791 by Wichman yet, little progress was made toward understanding the mechanism of this disease until the 20th century. Today, pemphigus refers to a group of autoimmune diseases of the skin characterized by loss of normal cell-cell adhesion (acantholysis), that prompts to clinical blister development. In 1964, Beutner and Jordon discovered that patients suffering from pemphigus had IgG autoantibodies directed against the surface of keratinocytes (Beutner and Jordon 1964). In the late 1970 s to early 1980 s, studies showing that pemphigus autoantibodies related to blister formation in skin organ culture systems as well as by passively transferring $\mathrm{IgG}$ fractions of patients with pemphigus vulgaris into neonatal mice contributed to our understanding of disease pathogenesis (Schiltz and Michel 1976; Anhalt et al 1986). In the midto late $1980 \mathrm{~s}$, target antigens underwent immunochemical characterization (Stanley et al 1982; Hashimoto et al 1990) while in 1991, studies revealed that target antigens were the cadherin-type adhesion molecules of desmosomes desmoglein 1 (DSG1) and DSG3, (Koch et al 1990, Amagai et al 1991).

\subsection{Pemphigus vulgaris: clinical picture}

Pemphigus is divided into three major variants: pemphigus vulgaris (PV) pemphigus foliaceus (PF) and paraneoplastic pemphigus (Anhalt et al 1990). Patients with PV develop flaccid, thin-walled, easily ruptured blisters that occur anywhere on the body skin surface as well as in the oral cavity. PV is associated with extensive erosions and painful lesions that bleed easily. PV can be lethal as the skin loses epidermal barrier function, resulting in fluid loss and superimposed bacterial infections (Kershenovich et al 2014; Santoro et al 2013; Ruocco et al 2013; Bystryn and Rudolph 2005).

1.3. Hallmark of Pemphigus vulgaris: IgG autoantibodies against desmogleins (DSGs).
The hallmark of pemphigus pathogenesis is the presence of $\mathrm{IgG}$ autoantibodies against cell-surface antigens of keratinocytes. Molecular cloning of cDNAs encoding pemphigus antigens showed that patient-derived IgG autoantibodies recognize DSGs, (transmembrane desmosomal

glycoproteins) founded in the adhering junctions, the desmosomes. Desmosomes are dynamic complexes consisting of the DSG and desmocollins (DSC), which are cadherin-type adhesion molecules that are tethered to the cytoskeleton via interactions with plakoglobin and desmoplakin (Figure 1) (Kochet et al 1990; Amagai et al 1991).

Cadherins are a family of calciumdependent adhesion molecules that play fundamental role in the maintenance of tissue integrity (Spindler and Waschke 2014). All members of the cadherin family consist of conserved repeated amino-acid sequences with calcium-binding motifs in their extracellular domains. These well-conserved cytoplasmic domains are associated with $\alpha$-catenin, $\beta$ catenin, and plakoglobin, which are involved in regulatory mechanisms and mediate binding to the structural cytoskeleton network. Consequently, cadherins achieve strong cell-cell adhesion with resultant cellular morphological changes. In contrast, calcium-independent cell adhesion molecules, such as those of the immunoglobulin superfamily, elicit simple interactions and do not involve morphological changes of cells. Classical cadherins form parallel cis-dimers as a functional unit, and each individual dimer interacts with opposite strand dimers on another cell through an adhesion interface of the N-terminal domain (EC1) (AlJassar et al 2014).

$\mathrm{PV}$ is caused by autoantibodies mainly against DSG3, resulting in depletion of desmoglein from the desmosome and loss of cell adhesion. Current treatments for pemphigus involve blockade of antibody production, but these approaches are associated with potentially fatal infection. Non-immunosuppressive mechanisms for strengthening desmosomal cell adhesion would be beneficial, offering an 


\section{Is Endoplasmic Reticulum Stress linked to the Pathogenesis of Pemphigus Vulgaris?}

adjunctive strategy to block the pathogenic effects of pemphigus autoantibodies on skin integrity. Toward this direction, signaling pathways, such as that of p38 mitogen-induced protein kinase, have been shown to modulate keratinocyte cell adhesion in the autoimmune response in PV patients (Figure 2) (Sharma et al 2007).

Additionally, peptides targeting the DSG adhesive interface, confer resistance to PV IgG-induced blistering (Spindler et al 2013).

In $\mathrm{PF}$, pathogenic IgG autoantibodies directed against DSG-1, induce loss of adhesion in the subcorneal region of the epidermis, whereas, autoantibodies to DSG-3 in mucosal PV inhibit the proper function of desmosomes inducing the characteristic histologic feature of the disease, the intraepithelial acantholysis (Amagai et al 1998; Koulu et al 1984). However, more than half of PV sera also contain antibodies against DSG1. Most patients with early PV and only mucous membrane lesions have only anti-DSG3 antibodies, whereas most patients with later disease, involving the skin, have both anti-DSG3 and anti-DSG1 antibodies (Waschke and Spindler 2014; Malheiros et al 2014). Thus, it is likely that the production of anti- DSG1 autoantibodies signifies the transition off of the disease at more advanced stages.

1.4. Signal Transduction in Pemphigus
vulgaris proposed to explain how pemphigus autoantibodies disrupt keratinocyte cell-cell adhesion. The injection of $\mathrm{IgG}$ fractions from pemphigus patients into neonatal mice, cause blister formation in mouse skin reproducing the histology, immunohistology, mimicking the human disease.

The Kitajima's group was the first to demonstrate increased intracellular calcium levels in keratinocytes treated with sera from PV patients (Seishima et al 1995). In subsequent studies using either PV sera or fractions enriched for pathogenic $\mathrm{IgG}$, they showed activation of additional signaling molecules, including protein kinase C (Osada et al 1997) and phospholipase C
(Aoyama et al 1999). Other signaling events have been observed in pemphigus-treated keratinocytes and may contribute to loss of cell adhesion or to biologic transitions induced by altering cell interaction (Waschke et al 2006; Caldelari et al 2001; Calkins et al 2006). Moreover, Ishii et al. showed that when antiDSG3 IgG were removed by immuno-adsorption against the recombinant DSG3 the pathogenic effects were from PV patients (Ishii et al.1997).

These findings are supported by in vitro studies showing that monoclonal antibodies against DSG3 and recombinant single chain monovalent antibody fragments of PV patient antibodies disrupt desmosomal adhesion in neonatal and adult mouse PV models (Mascaro et al 1997; Payne et al 2005; Tsunoda et al 2003). Pathogenic monoclonal antibodies cloned from PV patients as well as experimentally produced antibodies against DSG3 which cause loss of adhesion, are typically targeted against the amino-terminal adhesive domains of DSG3 (Payne et al 2005; Tsunoda et al 2003). Collectively, these findings suggest that PV IgG leads to loss of adhesion in patients by sterically disrupting DSG3 adhesive interactions (Berkowitz et al 2005).

While these observations strongly support the link between anti-DSG antibodies and tissue (mucosal) dysfunction, their consequences at the cellular level remain obscure. Several findings challenge the monopathogenic etiology of pemphigus due to steric hindrance. For instance, negative regulation of signaling pathways or blockade of DSG3 endocytosis can stop PV IgG-induced loss of adhesion in both cell culture and animal model systems (Ramoni et al 2004). Protein kinase C (PKC), RhoA, c-myc, and tyrosine kinase pathways have been associated with the signaling cascade promoting loss of adhesion in keratinocytes treated with PV IgG (Figure 2) (Spindler and Waschke 2011). In addition p38 MAPK has been associated to both DSG3 endocytosis cell-cell adhesion and the loss of keratinocyte adhesion in response to PV $\operatorname{IgG}$ (Jolly et al 2010). However, recent studies reported that $\mathrm{p} 38$ alpha MAPK null mice treated with pathogenic PV DSG3 autoantibodies continue to exhibit blistering in response to 


\section{Is Endoplasmic Reticulum Stress linked to the Pathogenesis of Pemphigus Vulgaris?}

mechanical stress, indicating that p38 MAPK may not be necessary mediator for these antibodies to disrupt epidermal adhesion in vivo (Mao et al 2011).

\section{Endoplasmic reticulum (ER) stress signaling networks}

The endoplasmic reticulum (ER) is a major organelle that is instrumental for the processing of newly synthesized tail-anchored secreted and transmembrane proteins. To ensure efficient protein-folding, the ER provides a unique environment to create the balance between the ER protein load and the ER folding capacity. Multiple pathological and physiological insults affect the sensitive folding environment of the ER: Those include a large biosynthetic load, inflammatory cytokines, environmental toxins, viral infections and mutant protein expression leading to an accumulation of misfolded and unfolded proteins in the ER lumen, termed ER stress (Ron and Walter 2007; Rutkowski and Kaufman 2007).

The adaptive response triggered by ER stress is the well orchestrated unfolded protein response (UPR). UPR provides a cytoprotective mechanism by which cells maintain protein homeostasis. UPR includes four distinct responses: 1) up-regulation of molecular chaperones and enzymatic processing of proteins to increase the folding activity and ER' $s$ handling efficiency, 2) prevention of further protein synthesis and thus accumulation of unfolded proteins, by inhibiting mRNA translation, 3) enhancement of the ER-associated protein degradation (ERAD) and autophagy pathways to promote clearance of unfolded proteins, and finally, 4) induction of apoptosis when ER stress conditions are unreasonable. Negative feedback of UPR activation is needed to maintain cellular homeostasis. UPR regulates both apoptotic and anti-apoptotic pathways, acting as a binary switch between the life and death decisions of ER stressed cells. When the cells undergo short term or mild ER stress and the UPR is properly balanced, cells survive. However, during unresolvable ER stress the UPR is unbalanced leading to cell death (Ron and Walter 2007; Rutkowski and Kaufman 2007).

Mammalian UPR is initiated by three ER transmembrane protein regulators: the PKRlike ER kinase (PERK), the Activating Transcription Factor 6 (ATF6) and Inositol Requiring 1 (IRE1). According to the most widely accepted model, upon unstressed conditions, the ER chaperone, immunoglobin binding protein $(\mathrm{BiP})$ binds to the luminal domains of these master sensors, IRE1, PERK and ATF6, keeping them in their monomeric inactive forms. Under, ER stress conditions, BiP dissociates from IRE1, PERK and ATF6 sensors triggering unique downstream responses (Figure 4) (Rutkowski and Kaufman 2007).

A central regulator of ER stressassociated signaling is the type I ER transmembrane transcription factor, IRE1 (Urano et al 2000). Irel's cytosolic RNase domain cleaves an intron out of the mRNA of the XBP1, leading to the production of a potent transcriptional activator for genes encoding for several chaperones. The active RNase also cleaves ER-localized messages, including genes that function in ERAD such as ER-degradationenhancing- $\alpha$-mannidose-like protein (EDEM) leading to their degradation, to reduce the load of unfolded proteins entering the ER (Yoshida et al 2001; Shen et al 2001; Calfon et al 2002, Yoshida et al 2003). Spliced XBP1 mRNA induce the expression of genes encoding for folding proteins such as protein disulfide isomerase (PDI) (Lee et al 2003). Chronic stress, promotes the recruitment of TNF-receptorassociated factor 2 (TRAF2) via IRE1 and the induction of apoptosis-signaling-kinase 1 (ASK1). Activated ASK1 enhances c-Jun Nterminal protein kinase (JNK) eventually leading to apoptosis (Figure 4) (Urano et al 2000; Nishitoh et al 2002).

UPR induction also triggers PERK activation (Harding et al 1999). PERK is a type I ER transmembrane kinase, oligomerizes, autophosphorylates and then directly phosphorylates Ser51 on the $\alpha$ subunit of eukaryotic initiation factor 2 (eIF2 $\alpha$ ) (Harding et al 2000). Phosphorylated eIF2 $\alpha$ promotes global mRNA translational attenuation and recognition of AUG initiation codons leading to a reduction 


\section{Is Endoplasmic Reticulum Stress linked to the Pathogenesis of Pemphigus Vulgaris?}

in ER workload and thus protecting cells from ER stress-mediated apoptosis. Meanwhile, some mRNAs require eIF2 $\alpha$ phosphorylation for translation such as the mRNA encoding activating transcription factor 4 (ATF4). ATF4 is a b-ZIP transcription factor that regulates several UPR target genes, including those involved in ER stress mediated apoptosis such as $\mathrm{C} / \mathrm{EBP}$ homologous protein (CHOP) and growth arrest and DNA damage inducible gene 34 (GADD34), as well as genes involved in redox balance and amino acid synthesis (Figure 4) (Harding et al 2000).

The third regulator of ER stress signaling is ATF6. Upon sensing stress, ATF6 $\alpha$ transits to the Golgi where it is cleaved by site 1 (S1) and site 2 (S2) proteases, resulting in an activated b-ZIP factor (Yoshida et al 1998). This form of ATF6 $\alpha$ translocates to the nucleus to trigger activation of UPR target genes involved in protein folding, processing, and degradation (ERAD) (Ye et al 2000). Two isoforms of ATF6, ATF6 $\alpha$ and ATF6 $\beta$, with fairly ubiquitous tissue distribution have been extensively studied in the context of ER stress. The ATF6 $\alpha$ isoform has been shown to be responsible for transcriptional induction of ER chaperones. It has been reported that unprocessed ATF6 is unstable and rapidly degraded by the ubiquitin-proteasome pathway to prevent hyper-activation of the UPR (Figure 4) (Hong et al 2004).

An important aspect of ER stress regulation and transition from its prosurvival towards its pro-apoptotic activity is the negative regulation of $\mathrm{p} 21$ by $\mathrm{CHOP}$. The former is antiapoptotic and its suppression by $\mathrm{CHOP}$ facilitates the proapoptotic effects of $\mathrm{CHOP}$ (Mihailidou et al 2010; Mihailidou ${ }^{a}$ et al 2015; Mihailidou ${ }^{b}$ et al 2015)

\section{Endoplasmic reticulum (ER) stress linked} to pemphigus vulgaris $(\mathrm{PV})$

3.1. Deregulation of UPR activation in the autoimmune disease Pemphigus Vulgaris

Cell fate regulation by the UPR plays an instrumental role in ER stress-related physiological function and pathogenesis. ER stress has been linked to a variety of pathological conditions ranging from diabetes to neurodegenerative diseases and cancer, while recent data also linked UPR to PV (Sugiura et al 2009). PERK is activated in cultured keratinocytes, as shown by induction of phosphorylation of PERK and its downstream target eIF2a, in response to PV serum implying a link between ER stress and PV pathogenesis. Interestingly, depletion of sera from IgGs, but not PV IgGs also induced PERK activation, suggesting that IgG-independent factors are responsible for PERK activation during ER stress (Lanza et al 2011). Recent findings also demonstrate that non-immunoglobulin factors in PV serum promote metabolic stress and other changes in keratinocytes including reduction of cell viability and weakening of intercellular adhesion (Lanza et al 2011). Both alterations contribute to apoptolysis and cell-cell detachment. This, in part, is due to a direct effect on mitochondrial activity, but may also involve sensitization of mitochondria to the apoptotic pathway triggered by IgG. Apoptolysis in PV encompasses both antibody-mediated and nonantibody-mediated mechanisms,

demonstrating that the protein kinase PERK is a key molecule that mediates a stress response in PV and, ultimately, acantholysis (Lanza et al 2011; Cirillo et al 2007).

An earlier report suggested that, expression of UPR activation sensors Bip/GRP78, HRD1, PDI, and CHOP/ GADD153 was enhanced in the supra-basal layers of the epidermis. Moreover, in undifferentiated, atypical keratinocytes of PV tissues, Bip/GRP78 and HRD1 were expressed at lower levels than in normal differentiating keratinocytes. In normal human skin equivalents, these two antigens were upregulated in the upper layers, and there were higher mRNA levels of CHOP/GADD153, Bip/GRP78, $\mathrm{PDI}$, and $\mathrm{XBP}-1(\mathrm{~S})$ in 14-day multilayer cultured keratinocytes than in 3-day cultured keratinocytes. Furthermore, in PD1-treated keratinocytes, a model of keratinocyte differentiation, Bip/GRP78, CHOP/GADD153, XBP-1(S) and PDI were enhanced. Thus, this study supports the notion that the UPR is activated in differentiating $\mathrm{KCs}$ in comparison with proliferating keratinocyte (Sugiura et al 2009). 


\section{Is Endoplasmic Reticulum Stress linked to the Pathogenesis of Pemphigus Vulgaris?}

In a more recent study, the prevalence of ER stress induction in oral biopsy specimens from PV patients was assessed, by evaluating the expression of BiP/GRP78, by immunohistochemistry. Intense cytoplasmic staining of BiP/GRP78 in the acantholytic cells of the epithelium was detected indicating that acantholytic cells are under ER stress. Conventionally ER stress is linked to the accumulation of unfolded and misfolded proteins due to various extrinsic and intrinsic factors that can involve changes in the cells' supply of nutrients and exposure to conditions that directly or indirectly affect cellular homeostasis. During acantholysis it is conceivable that cells may undergo ER stress in part because the detachment from the basal membrane alters nutrient supply and normal cell growth (Mihailidou et al 2016).

\subsection{UPR activation by anti-DSG1 and anti- DSG3 antibodies.}

The hallmark of PV pathogenesis is the presence of anti-DSG autoantibodies. As already described both anti-DSG1 and anti-DSG3 autoantibodies have been linked to PV with antiDSG3 being considered causative for disease development and anti-DSG1 being identified in the most aggressive types. In the presence of increasing concentrations of anti-DSG1 antibody $\mathrm{HaCaT}$ keratinocytes exhibited altered the expression of BiP/GRP78, GRP94, calnexin and CHOP. Lower concentrations, of anti-DSG3 exhibited the same expression profile with control IgG suggesting that they are incapable of eliciting specifically the UPR. However, antiDSG1 activated GRP94, BiP/GRP78 and calnexin expression suggesting that the UPR is induced. CHOP expression was also stimulated by anti-DSG1 in a dose responsive manner. The observation though that neither anti-DSG3 nor control IgG stimulated CHOP argues in favor of the specificity of CHOP induction by antiDSG1. This observation is in line with earlier observations on the significance of DSG1 in HaCaT cells and may also imply a specific role for DSG1 in ER stress (Mihailidou et al 2016).

3.3. Effects of ER-stress inhibition in antiDSG1 and anti-DSG3 - mediated cytotoxicity

Cell survival assays have shown that both anti-DSG1 and anti-DSG3 - albeit at a lesser extent - were cytotoxic in HaCaT cells. In this model of cultured keratinocytes the formation of cell adhesion does not play a direct role in cell viability, thus cytotoxicity is not directly linked to the loss of desmosome function. Importantly, ablation of CHOP expression partially restored cell survival only for anti-DSG1. In view of the role of CHOP in mediating the proapoptotic effects of ER stress, it has been suggested that anti-DSG1-related, but not anti-DSG3-related cytotoxicity was associated with UPR induction. The partial restoration of cell viability by siRNA for CHOP reflecting the canonical UPR-associated indicates the operation of more wide effects of anti-DSGs in cell viability. Of those, only the former (UPR - related) are linked to anti-DSG1 and depend on CHOP while the latter are inflicted by both anti-DSG1 and anti-DSG3 and appear to be CHOP-independent. To that end anti-DSG1 may induce ER stress.

In an earlier study (Lanza et al 2011), it has been demonstrated that PV sera enhanced PERK activation. Noteworthy, depletion of $\operatorname{IgG}$ from the sera, as well as IgGs fractions purified from PV patient sera was unable to activate PERK and affect cell viability suggesting that non-IgG factors are responsible for these effects (Lanza et al 2011). The ability of anti-DSG1 to regulate cell viability may be due to the fact that IgG fractions, in addition to the anti-DSGs of interest may also contain mitogenic IgGs and other soluble factors that by acting in an opposite manner can mask the anti-proliferative effects of the former (Waschke et al 2005). Moreover, it is possible that the cell viability assays took into consideration cytostatic, as opposed to merely cytotoxic effects (Mihailidou et al 2016).

\section{Future Directions and Conclusions}

The UPR participates in the regulation of a wide range of inputs and outputs enabling the cell to respond to a number of diverse stimuli and cellular states. Many questions remain regarding if the pathogenesis of $\mathrm{PV}$ is affected by ER stress and whether PV activates only the one pathway of ER stress response, or all three arms of the UPR are being activated. Moreover, few studies evaluate the PV blistering associated 


\section{Is Endoplasmic Reticulum Stress linked to the Pathogenesis of Pemphigus Vulgaris?}

with ER stress activation (Figure 5). Since interference with ER stress induction reduced anti-DSG1-induced cytotoxicity, suggests that manipulation of the UPR provides means for the management of PV. Furthermore, focused studies investigating ER stress in humans or humanized mice/ rodent models with PV will further improve our understanding of the UPR in
PV and provide fertile ground for future investigations.

\section{Acknowledgements}

This work was supported by an ASPIRE I award no:18060-16-41667 (to I.C.) from the Office of Research of the USC.

\section{Figure Legends}

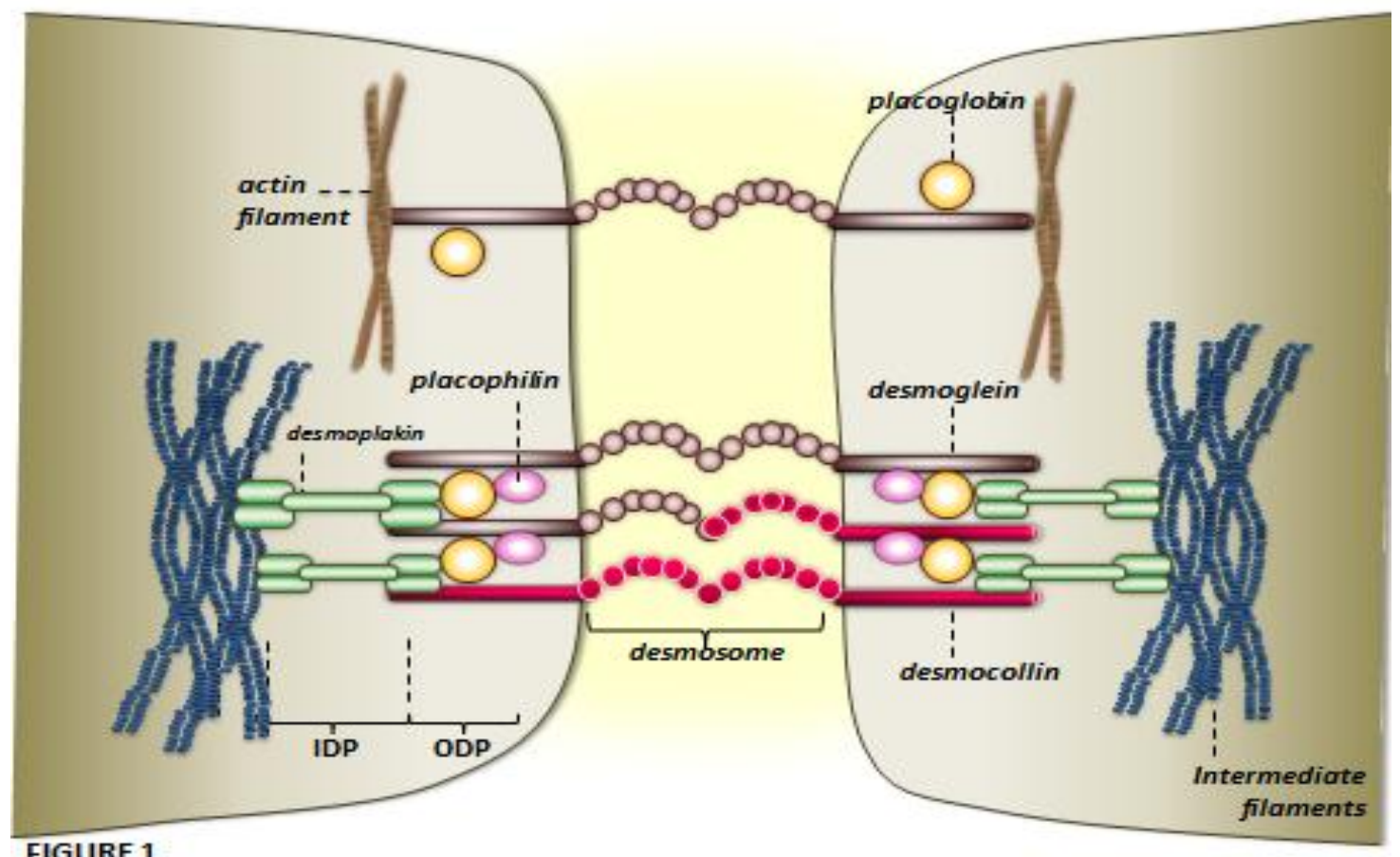

\section{FIGURE 1}

Figure 1: Molecular structure of the desmosome (modified from Waschke 2008).

Desmosomes are specific intercellular junctional complexes designed to tether adjacent keratinocytes together. Desmosomes are composed of cadherin-type transmembrane adhesion molecules cadherins (desmogleins and desmocollins). These adhesion molecules undergo homophilic and heterophilic binding mediated by interaction with the amino-terminal extracellular (EC1) domain of partner molecules on the same (cis) as well as on the neighboring cell (trans). Cytoplasmic domains of these molecules are intracellularly associated to the intermediate filament network in the outer dense plaque (ODP) via the adapter proteins plakoglobin, plakophilins and desmoplakin. In the inner dense plaque (IDP), desmoplakin binds these adaptor molecules to the intermediate filament cytoskeleton. 


\section{Is Endoplasmic Reticulum Stress linked to the Pathogenesis of Pemphigus Vulgaris?}

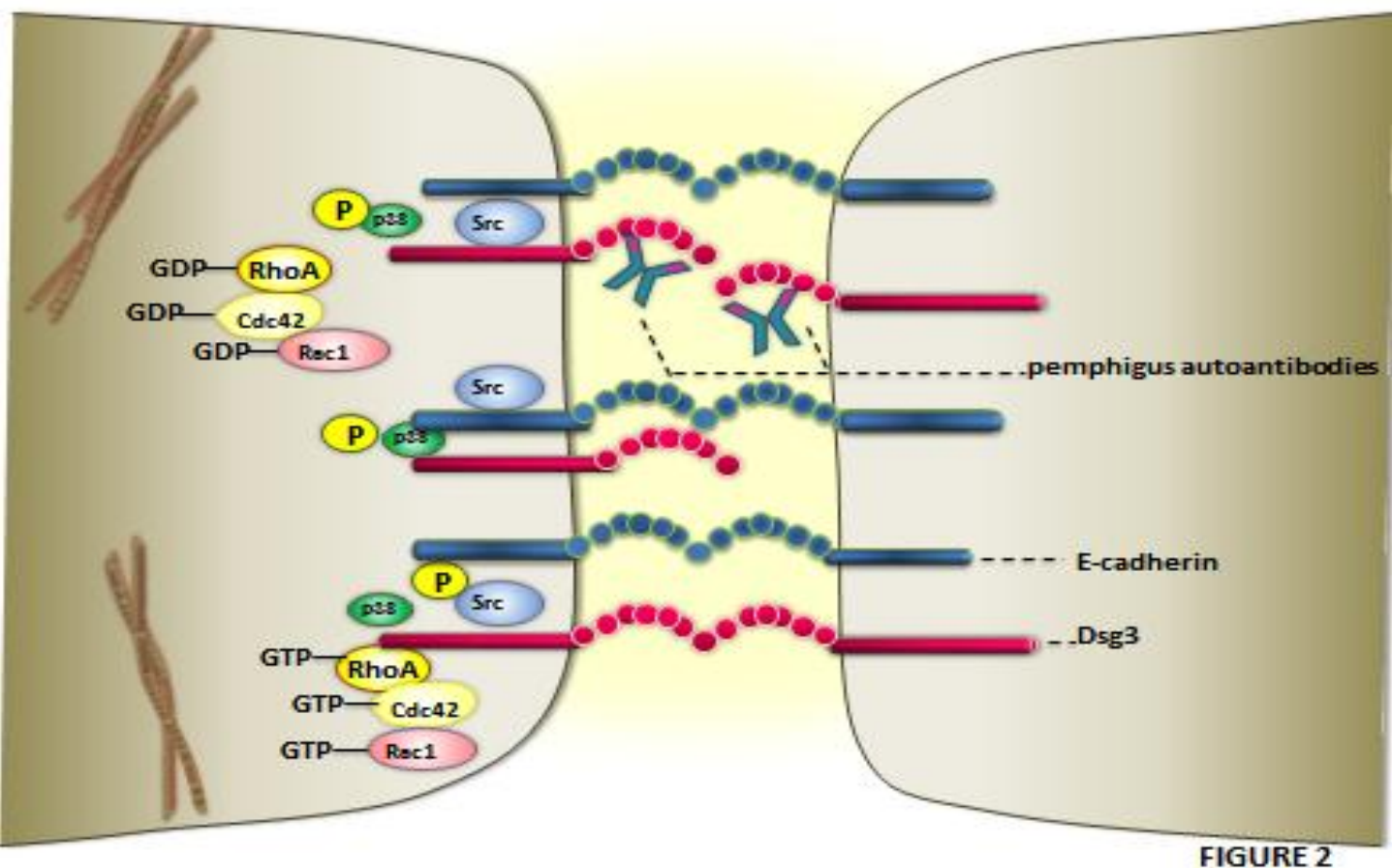

Figure 2 Desmogleins serve as signaling hubs (modified from Spindler and Waschke 2014)

Specifically desmogleins are known to exist "free" on the membrane and remain free of desmosomes. Desmosomal components are associated with a variety of signaling molecules such as and p38MAPK, Src and Rho-GTPases (RhoA, Rac1 and Cdc42Hs). By regulating the activity of these molecules, extradesmosomal desmogleins are required for signaling hubs to modulate cellular behavior. Upon autoantibody binding, p38MAPK is triggered within the signaling complex with Dsg3, a process involved in RhoA inhibition, which finally reduce the cytoskeletal anchorage of desmosomes. 


\section{Is Endoplasmic Reticulum Stress linked to the Pathogenesis of Pemphigus Vulgaris?}

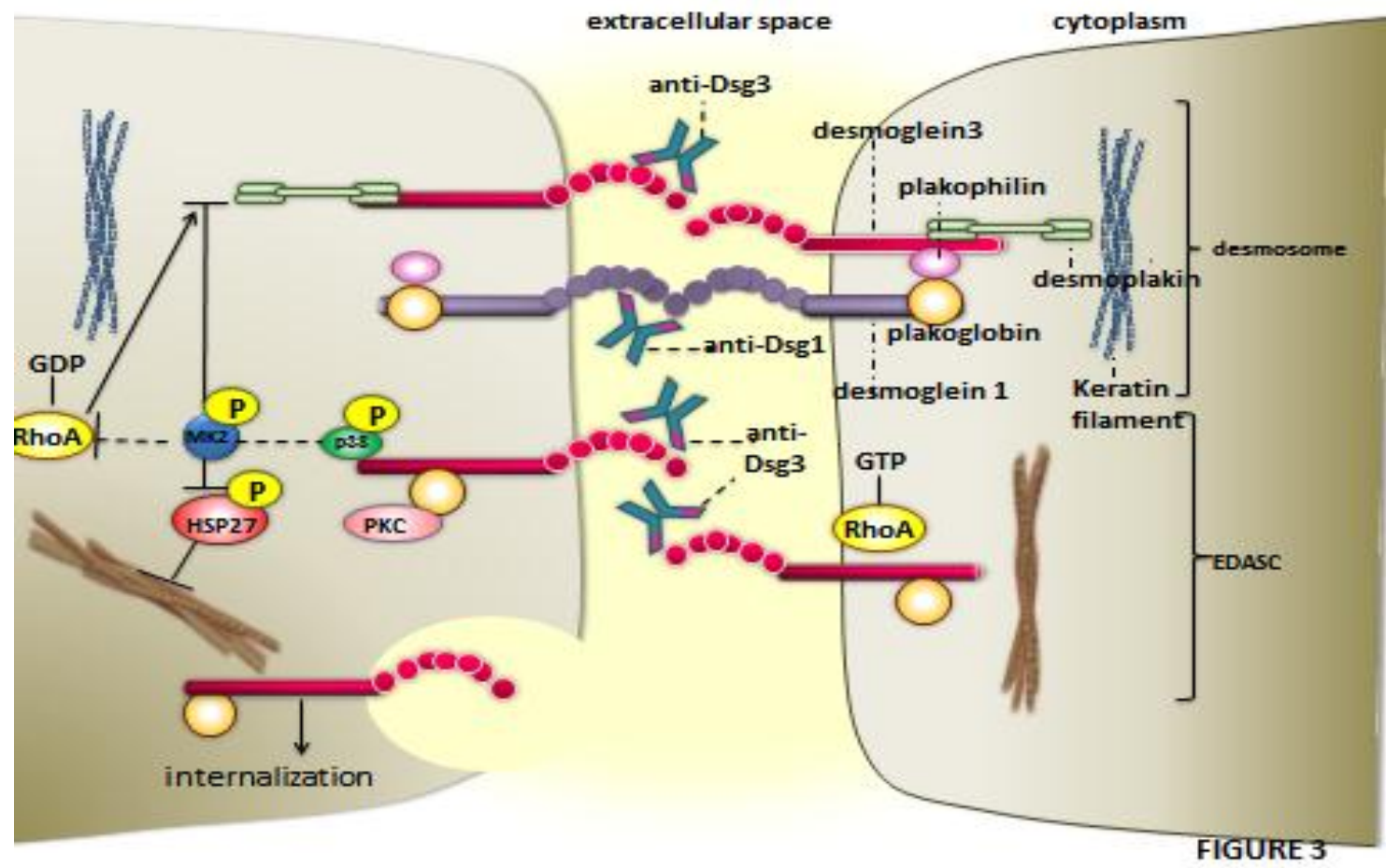

Figure 3 Mechanism of blister formation (modified from Spindler and Waschke 2014) Autoantibodies interfere with the binding of desmosome cadherin DSG3 and alter intracellular signaling by activating phosphorylation of p38MAPK, MAPKAP kinase 2, and HSP27 which is necessary for loss of cell adhesion, at least in part following the initial loss of DSG3 interaction. Furthermore, activation of PKC causes desmosomes to be less adhesive. All these trigger (i) loss of junctional DSG3 and other desmosomal molecules that attach the cell surface, (ii) uncoupling of the intermediate filament-desmosome association. These effects are thought to represent the main mechanisms of loss of cell-cell junctions and ultimately blister formation. 


\section{Is Endoplasmic Reticulum Stress linked to the Pathogenesis of Pemphigus Vulgaris?}

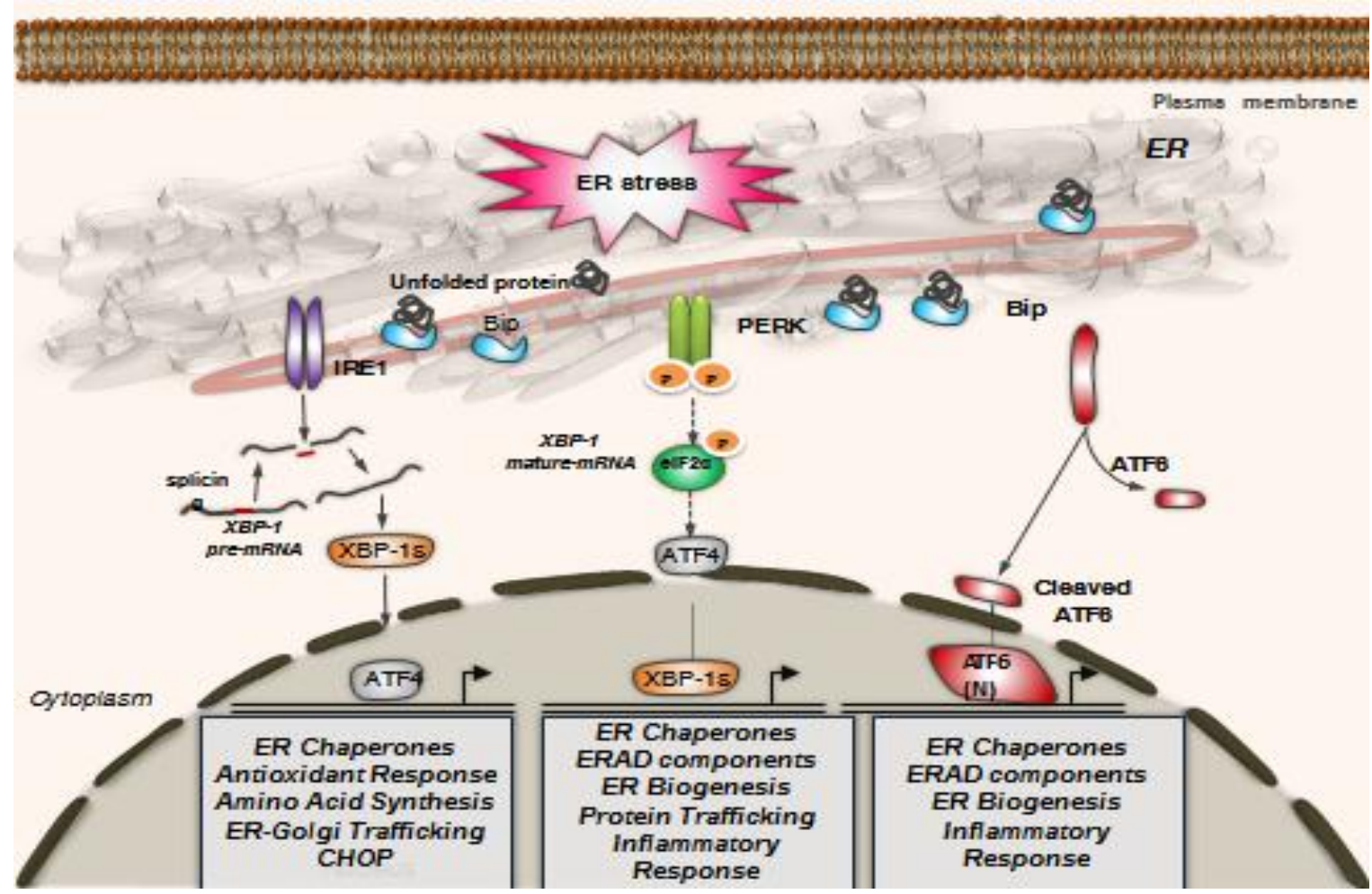

Figure 4 Pathways regulating $U P R$ responses In eukaryotic cells, UPR complex network is mediated by the ER-transmembrane proteins detecting ER stress: PKR-like endoplasmic reticulum kinase (PERK), Inositol-Requiring 1 (Ire1) and Activating Transcription Factor 6 (ATF6). All these stress sensor molecules normally held in an inactive and inhibited state by the binding of GRP78/BiP. Upon ER-stress GRP78 is released and preferentially binds to misfolded/ unassembled unfolded proteins accumulating in the ER lumen, promoting the activation of the UPR. 
Medical Research Archives, Volume 4 ,Issue 7.

Is Endoplasmic Reticulum Stress linked to the Pathogenesis of Pemphigus Vulgaris?

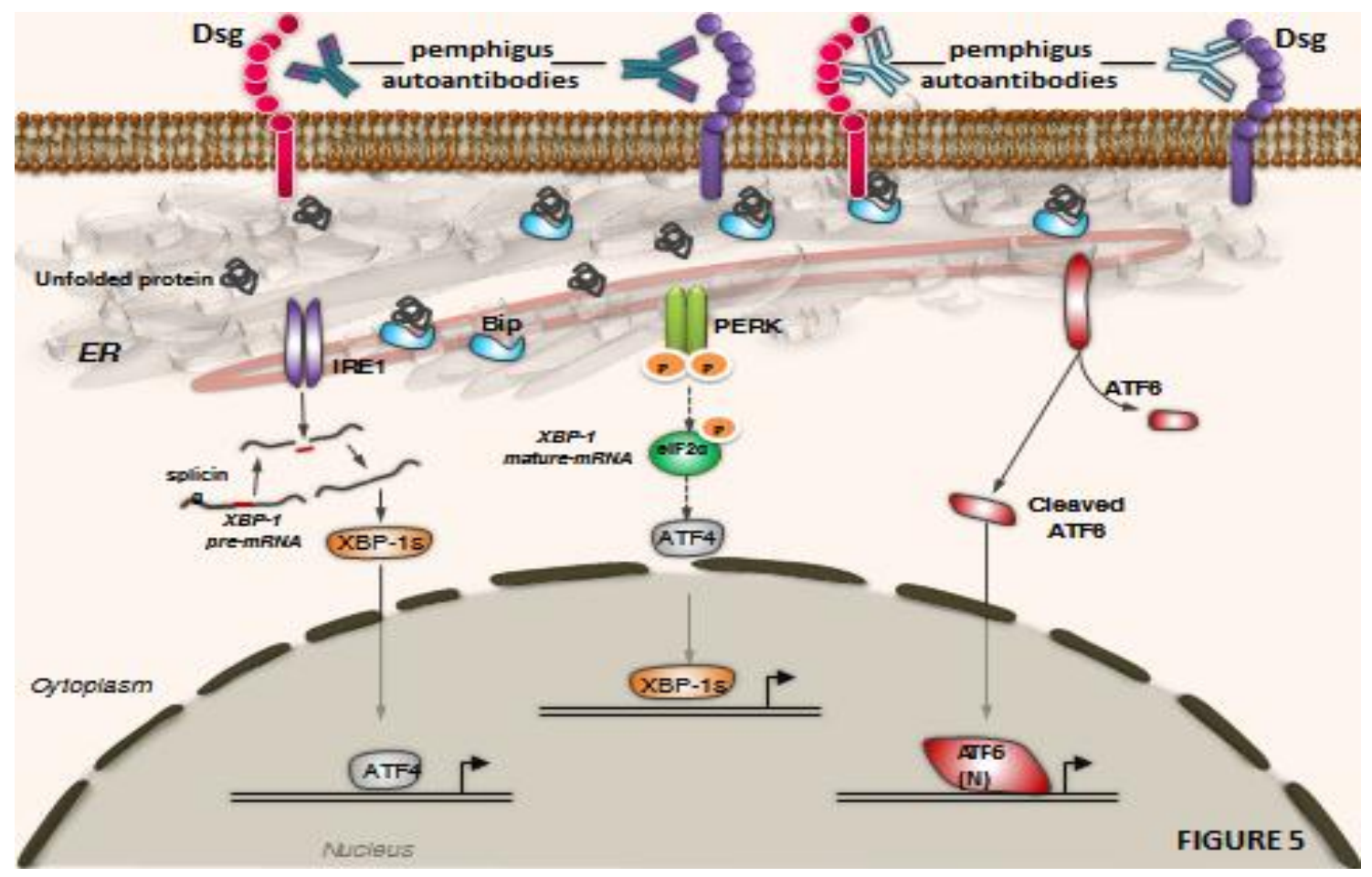

Figure 5 Endoplasmic reticulum (ER) stress associated with pemphigus vulgaris $(P V)$

Pemphigus vulgaris is characterized by the presence of auto-antibodies against desmogleins

(DSG) -3 and -1 , and recent evidence indicated that the Endoplasmic Reticulum (ER) stress may be a key component in the complex pathogenesis of pemphigus vulgaris. 


\section{Is Endoplasmic Reticulum Stress linked to the Pathogenesis of Pemphigus Vulgaris?}

\section{References}

1. Al-Jassar C, Bikker H, Overduin M, Chidgey M. (2013) Mechanistic basis of desmosome-targeted diseases. J. Mol. Biol. 425, 4006-4022.

2. Amagai M., Klaus-Kovtun V., Stanley J.R. (1991) Autoantibodies against a novel epithelial cadherin in pemphigus vulgaris, a disease of cell adhesion. Cell. $67,869-877$

3. Amagai, M., Nishikawa, T., Nousari, H. C., Anhalt, G. J., \& Hashimoto, T. (1998). Antibodies against desmoglein 3 (pemphigus vulgaris antigen) are present in sera from patients with paraneoplastic pemphigus and cause acantholysis in vivo in neonatal mice. Journal of Clinical Investigation, 102(4), 775-782. http://doi.org/10.1172/JCI3647

4. Anhalt G.J., Kim S., Stanley J.R., Korman N.J., Jabs D.A., Kory M., et al. (1990) Paraneoplastic pemphigus. An autoimmune mucocutaneous disease associated with neoplasia.N. Engl. J. Med.323, 1729-1735

5. Anhalt G.J., Labib R.S., Voorhees J.J., Beals T.F., Diaz L.A. (1982) Induction of pemphigus in neonatal mice by passive transfer of $\mathrm{IgG}$ from patients with the disease. N. Engl. J. Med. 306, 1189-1196

6. Aoyama, Y., Owada, M. K., \& Kitajima, Y. (1999). A pathogenic autoantibody, pemphigus vulgaris-IgG, induces phosphorylation of desmoglein 3 , and its dissociation from plakoglobin in cultured keratinocytes. European Journal of Immunology, 29(7), 22332240.

http://doi.org/10.1002/(SICI)1521-

4141(199907)29:07<2233::AID-

IMMU2233>3.0.CO;2-4

7. Berkowitz, P., Hu, P., Liu, Z., Diaz, L. A., Enghild, J. J., Chua, M. P., \& Rubenstein, D. S. (2005). Desmosome signaling: Inhibition of p38MAPK prevents pemphigus vulgaris IgG- induced cytoskeleton reorganization. Journal of Biological Chemistry, 280(25), 23778-23784. http://doi.org/10.1074/jbc.M501365200

8. Beutner E.H., Jordon R.E. (1964) Demonstration of skin antibodies in sera of pemphigus vulgaris patients by indirect immunofluorescent staining. Proc. Soc. Exp. Biol. Med, 117, 505-510

9. Bystryn, J. C., \& Rudolph, J. L. (2005). Pemphigus. In Lancet (Vol. 366, pp. 6173).

10. Caldelari, R., De Bruin, A., Baumann, D., Suter, M. M., Bierkamp, C., Balmer, V., \& Müller, E. (2001). A central role for the armadillo protein plakoglobin in the autoimmune disease pemphigus vulgaris. Journal of Cell Biology, 153(4), 823-834. http://doi.org/10.1083/jcb.153.4.823

11. Calfon, M., Zeng, H., Urano, F., Till, J. H., Hubbard, S. R., Harding, H. P., Ron, D. (2002). IRE1 couples endoplasmic reticulum load to secretory capacity by processing the XBP-1 mRNA. Nature, 415(6867), 92-96. http://doi.org/10.1038/nature01193

12. Calkins, C. C., Setzer, S. V., Jennings, J. M., Summers, S., Tsunoda, K., Amagai, M., \& Kowalczyk, A. P. (2006). Desmoglein endocytosis and desmosome disassembly are coordinated responses to pemphigus autoantibodies. Journal of Biological Chemistry, 281(11), 7623-7634. http://doi.org/10.1074/jbc.M512447200

13. Cirillo, N., Lanza, M., Femiano, F., Gaeta, G. M., De Rosa, A., Gombos, F., \& Lanza, A. (2007). If pemphigus vulgaris $\operatorname{IgG}$ are the cause of acantholysis, new IgG-independent mechanisms are the concause. Journal of Cellular Physiology, 212(3), 563567. http://doi.org/10.1002/jcp.21111

14. Harding, H. P., Novoa, I., Zhang, Y., Zeng, H., Wek, R., Schapira, M., \& 


\section{Is Endoplasmic Reticulum Stress linked to the Pathogenesis of Pemphigus Vulgaris?}

Ron, D. (2000). Regulated Translation Initiation Controls Stress-Induced Gene Expression in Mammalian Cells. Molecular Cell, 6(5), 1099-1108. http://doi.org/10.1016/S10972765(00)00108-8

15. Harding, H. P., Zhang, Y., \& Ron, D. (1999). Protein translation and folding are coupled by an endoplasmicreticulum-resident kinase. Nature, 397(6716), 271-274. http://doi.org/10.1038/16729

16. Harding, H. P., Zhang, Y., Bertolotti, a, Zeng, H., \& Ron, D. (2000). Perk is essential for translational regulation and cell survival during the unfolded protein response. Molecular Cell, 5(5), 897904. http://doi.org/10.1016/S10972765(00)80330-5

17. Hashimoto T., Ogawa M.M., Konohana A., Nishikawa T. (1990) Detection of pemphigus vulgaris and pemphigus foliaceus antigens by immunoblot analysis using different antigen sources. J. Invest. Dermatol. 94, 327-331

18. Hong, M., Li, M., Mao, C., \& Lee, A. S. (2004). Endoplasmic reticulum stress triggers an acute proteasome-dependent degradation of ATF6. Journal of Cellular Biochemistry, 92(4), 723-732. http://doi.org/10.1002/jcb.20118

19. Ishii, K., Amagai, M., Hall, R. P., Hashimoto, T., Takayanagi, A., Gamou, S., Nishikawa, T. (1997). Characterization of autoantibodies in pemphigus using antigen-specific enzyme-linked immunosorbent assays with baculovirus-expressed recombinant desmogleins. Journal of Immunology (Baltimore, Md.: 1950). http://doi.org/10.4049/jimmunol.100178 2

20. Jolly, P. S., Berkowitz, P., Bektas, M., Lee, H. E., Chua, M., Diazr, L. A., \& Rubenstein, D. S. (2010). p38MAPK signaling and desmoglein-3 internalization are linked events in pemphigus acantholysis. Journal of Biological Chemistry, 285(12), 8936-
8941.

http://doi.org/10.1074/jbc.M109.087999

21. Kershenovich R., Hodak E., Mimouni D. (2014) Diagnosis and classification of pemphigus and bullous pemphigoid. Autoimmun. Rev. 13, 477-81.

22. Koch P.J., Walsh M.J., Schmelz M., Goldschmidt M.D., Zimbelmann R., Franke W.W. (1990) Identification of desmoglein, a constitutive desmosomal glycoprotein, as a member of the cadherin family of cell adhesion molecules. Eur. J. Cell Biol. 53, 1-12 [PubMed]

23. Koulu, L., Kusumi, A., Steinberg, M. S., Klaus-Kovtun, V., \& Stanley, J. R. (1984). Human autoantibodies against a desmosomal core protein in pemphigus foliaceus. J Exp Med, 160(5), 15091518.

http://doi.org/10.1084/jem.160.5.1509

24. Lanza, A., Lanza, M., Santoro, R., Soro, V., Prime, S. S., \& Cirillo, N. (2011). Deregulation of PERK in the autoimmune disease pemphigus vulgaris occurs via IgG-independent mechanisms. British Journal of Dermatology, 164(2), 336-343. http://doi.org/10.1111/j.13652133.2010.10084.x

25. Lee, A.-H., Iwakoshi, N. N., \& Glimcher, L. H. (2003). XBP-1 regulates a subset of endoplasmic reticulum resident chaperone genes in the unfolded protein response. Molecular and Cellular Biology, 23(21), 7448-59. http://doi.org/10.1128/MCB.23.21.7448

26. Malheiros, D., Panepucci, R. A., Roselino, A. M., Araújo, A. G., Zago, M. A., \& Petzl-Erler, M. L. (2014). Genome-wide gene expression profiling reveals unsuspected molecular alterations in pemphigus foliaceus. Immunology, 143(3), 381-395. http://doi.org/10.1111/imm.12315

27. Mao, X., Sano, Y., Park, J. M., \& Payne, A. S. (2011). p38 MAPK activation is downstream of the loss of intercellular 


\section{Is Endoplasmic Reticulum Stress linked to the Pathogenesis of Pemphigus Vulgaris?}

adhesion in pemphigus vulgaris. Journal of Biological Chemistry, 286(2), 12831291.

http://doi.org/10.1074/jbc.M110.172874

28. Mascaro JM Jr, Espana A, Liu Z, Ding X, Swartz SJ, et al. (1997) Mechanisms of acantholysis in pemphigus vulgaris: role of $\mathrm{IgG}$ valence. Clin Immunol Immunopathol. 85: 90-96

29. Mihailidou C, Katsoulas N, Panagiotou E, Farmaki E, Sklavounou A, Kiaris H, Chatzistamou I. (2016) Endoplasmic Reticulum stress is associated with the pathogenesis of Pemphigus Vulgaris. Exp Dermatol. Apr 6. doi: 10.1111/exd.13026.

30. Mihailidou C., Papazian I., Papavassiliou A. G., Kiaris H. (2010) CHOP-dependent Regulation of p21/waf1 During ER Stress. Cell Physiol Biochem, 25(6),761-6.

31. Mihailidou, $C^{\mathrm{a}}$., Chatzistamou, I., Papavassiliou, A. G., \& Kiaris, H. (2015). Regulation of P21 during diabetes-associated stress of the endoplasmic reticulum. EndocrineRelated Cancer, 22(2), 217-228. http://doi.org/10.1530/ERC-15-0018

32. Mihailidou, $\mathrm{C}^{\mathrm{b}}$., Chatzistamou, I., Papavassiliou, A. G., \& Kiaris, H. (2015). Improvement of

chemotherapeutic drug efficacy by endoplasmic reticulum stress. Endocrine-Related Cancer, 22(2), 229238. http://doi.org/10.1530/ERC-15$\underline{0019}$

33. Nishitoh, H., Matsuzawa, A., Tobiume, K., Saegusa, K., Takeda, K., Inoue, K., ... Ichijo, H. (2002). ASK1 is essential for endoplasmic reticulum stressinduced neuronal cell death triggered by expanded polyglutamine repeats. Genes and Development, 16(11), 1345-1355. http://doi.org/10.1101/gad.992302

34. Osada, K., Seishima, M., \& Kitajima, Y. (1997). Pemphigus $\mathrm{IgG}$ activates and translocates protein kinase $\mathrm{C}$ from the cytosol to the particulate/cytoskeleton fractions in human keratinocytes. $J$ Invest Dermatol, 108(4), 482-487. http://doi.org/S0022202X97801352 [pii]

35. Payne, A. S., Ishii, K., Kacir, S., Lin, C., Li, H., Hanakawa, Y., Siegel, D. L. (2005). Genetic and functional characterization of human pemphigus vulgaris monoclonal autoantibodies isolated by phage display. Journal of Clinical Investigation, 115(4), 888-899. http://doi.org/10.1172/JCI200524185

36. Ramoni, C., Spadaro, F., Barletta, B., Dupuis, M. L., \& Podo, F. (2004). Phosphatidylcholine-specific phospholipase $\mathrm{C}$ in mitogen-stimulated fibroblasts. Experimental Cell Research, 299(2), 370-382.

http://doi.org/10.1016/j.yexcr.2004.05.0 37

37. Ron, D., \& Walter, P. (2007). Signal integration in the endoplasmic reticulum unfolded protein response. Nature Reviews. Molecular Cell Biology, 8(7), 519-529. http://doi.org/10.1038/nrm2199

38. Ruocco V, Ruocco E, Lo Schiavo A, et al. (2013) Pemphigus: Etiology, pathogenesis, and inducing or triggering factors: Facts and controversies. Clin Dermatol. 31, 374-81.

39. Rutkowski, D. T., \& Kaufman, R. J. (2007). That which does not kill me makes me stronger: adapting to chronic ER stress. Trends in Biochemical Sciences.

http://doi.org/10.1016/j.tibs.2007.09.003

40. Santoro FA, Stoopler ET, Werth VP. Pemphigus.(2013) Dent. Clin. North Am. 57, 597-610.

41. Schiltz J.R., Michel B. (1976) Production of epidermal acantholysis in normal human skin in vitro by the $\mathrm{IgG}$ fraction from pemphigus serum. $J$. Invest. Dermatol. 67, 254-260

42. Seishima M, Esaki C, Osada K, Mori S, Hashimoto T, Kitajima Y. Pemphigus $\mathrm{IgG}$, but not bullous pemphigoid IgG, causes a transient increase in intracellular calcium and inositol 1,4,5trisphosphate in DJM-1 cells, a 


\section{Is Endoplasmic Reticulum Stress linked to the Pathogenesis of Pemphigus Vulgaris?}

squamous cell carcinoma line. (1995)Journal of Investigative Dermatology. 104(1),33-37. [PubMed]

43. Sharma P, Mao X, Payne AS. (2007) Beyond steric hindrance: The role of adhesion signaling pathways in the pathogenesis of pemphigus. $J$ Dermatol Sci. 48, 1-14.

44. Shen, X., Ellis, R. E., Lee, K., Liu, C. Y., Yang, K., Solomon, A., Kaufman, R. J. (2001). Complementary signaling pathways regulate the unfolded protein response and are required for $\mathrm{C}$. elegans development. Cell, 107(7), 893-903. http://doi.org/10.1016/S00928674(01)00612-2

45. Spindler V, Rotzer V, Dehner C, et al. (2013) Peptide-mediated desmoglein 3 crosslinking prevents pemphigus vulgaris autoantibody-induced skin blistering. J Clin Invest.

46. Spindler V, Waschke J. (2014) Desmosomal cadherins and signaling: lessons from autoimmune disease. Cell Commun Adhes. 21, 77-84

47. Spindler, V., \& Waschke, J. (2011). Role of Rho GTPases in desmosomal adhesion and pemphigus pathogenesis. Annals of Anatomy. http://doi.org/10.1016/j.aanat.2011.02.0 03

48. Stanley J.R., Yaar M., Hawley N.P., Katz S.I. (1982) Pemphigus antibodies identify a cell surface glycoprotein synthesized by human and mouse keratinocytes. J. Clin. Invest.70, 281288

49. Sugiura, K., Muro, Y., Futamura, K., Matsumoto, K., Hashimoto, N., Nishizawa, Y., Usukura, J. (2009). The unfolded protein response is activated in differentiating epidermal keratinocytes. The Journal of Investigative Dermatology, 129(9), 2126-35. http://doi.org/10.1038/jid.2009.51

50. Tsunoda, K., Ota, T., Aoki, M., Yamada, T., Nagai, T., Nakagawa, T., ... Amagai, M. (2003). Induction of pemphigus phenotype by a mouse monoclonal antibody against the aminoterminal adhesive interface of desmoglein 3. Journal of Immunology (Baltimore, Md.: 1950), 170, 21702178.

http://doi.org/10.4049/jimmunol.170.4.2 170

51. Urano, F., Bertolotti, a, \& Ron, D. (2000). IRE1 and efferent signaling from the endoplasmic reticulum. Journal of Cell Science, 113 Pt 21, 3697-3702.

52. Urano, F., Wang, X., Bertolotti, A., Zhang, Y., Chung, P., Harding, H. P., \& Ron, D. (2000). Coupling of stress in the ER to activation of JNK protein kinases by transmembrane protein kinase IRE1. Science (New York, N.Y.), 287(5453), 664-6.

http://doi.org/10.1126/science.287.5453. 664

53. Waschke, J. (2008). The desmosome and pemphigus. Histochemistry and Cell Biology. http://doi.org/10.1007/s00418008-0420-0

54. Waschke, J., \& Spindler, V. (2014). Desmosomes and Extradesmosomal Adhesive Signaling Contacts in Pemphigus. Medicinal Research Reviews, 34(6), 1127-1145. http://doi.org/10.1002/med.21310

55. Waschke, J., Bruggeman, P., Baumgartner, W., Zillikens, D., \& Drenckhahn, D. (2005). Pemphigus foliaceus $\mathrm{IgG}$ causes dissociation of desmoglein 1-containing junctions without blocking desmoglein 1 transinteraction. Journal of Clinical Investigation, 115(11), 3157-3165. http://doi.org/10.1172/JCI23475

56. Waschke, J., Spindler, V., Bruggeman, P., Zillikens, D., Schmidt, G., \& Drenckhahn, D. (2006). Inhibition of Rho A activity causes pemphigus skin blistering. Journal of Cell Biology, 175(5), 721-727. http://doi.org/10.1083/jcb.200605125

57. Ye, J., Rawson, R. B., Komuro, R., Chen, X., Dav??, U. P., Prywes, R., ... Goldstein, J. L. (2000). ER stress 


\section{Is Endoplasmic Reticulum Stress linked to the Pathogenesis of Pemphigus Vulgaris?}

induces cleavage of membrane-bound ATF6 by the same proteases that process SREBPs. Molecular Cell, 6(6), 13551364. http://doi.org/10.1016/S10972765(00)00133-7

58. Yoshida, H., Haze, K., Yanagi, H., Yura, T., \& Mori, K. (1998). Identification of the cis-acting endoplasmic reticulum stress response element responsible for transcriptional induction of mammalian glucoseregulated proteins: Involvement of basic leucine zipper transcription factors. Journal of Biological Chemistry, 273(50), 33741-33749. http://doi.org/10.1074/jbc.273.50.33741
59. Yoshida, H., Matsui, T., Hosokawa, N., Kaufman, R. J., Nagata, K., \& Mori, K. (2003). A time-dependent phase shift in the mammalian unfolded protein response. Developmental Cell. http://doi.org/10.1016/S15345807(03)00022-4

60. Yoshida, H., Matsui, T., Yamamoto, A., Okada, T., \& Mori, K. (2001). XBP1 mRNA is induced by ATF6 and spliced by IRE1 in response to ER stress to produce a highly active transcription factor. Cell, 107(7), 881-891. http://doi.org/10.1016/S00928674(01)00611-0 